\title{
BIORREMEDIACIÓN DE METALES PESADOS CADMIO (Cd), CROMO (Cr) Y MERCURIO (Hg) MECANISMOS BIOQUÍMICOS E INGENIERIAA GENÉTICA: UNA REVISIÓN
}

Fecha de recepción: 14 de marzo de 2016 • Fecha de Evaluación: 6 de junio de 2016 • Fecha de aceptación: 11 de junio de 2016 • Disponible en línea: 25 de julio de 2016

\author{
BIORREMEDIATION OF HEAVY METAL CADMIUM (Cd), CHROME (Cr) AND MERCURY (Hg), \\ BIOCHEMICAL MECHANISMS AND GENETIC ENGINEERING: A REVIEW
}

Mayra Eleonora Beltrán-Pineda', Alida Marcela Gómez-Rodríguez²

\section{RESUMEN}

Los metales pesados se consideran unos de los contaminantes más tóxicos en el ambiente por tener efectos nocivos a nivel de toda la cadena trófica, en especial el $\mathrm{Cd}$, $\mathrm{Cr}$ y Hg son relevantes debido su persistencia y toxicidad. En la actualidad existen diversas técnicas de tipo fisicoquímico utilizadas para el tratamiento de estas sustancias, las cuales han mostrado algunas deficiencias y efectos secundarios a largo plazo. Por esta razón la implementación de otro tipo de tecnologías que involucren seres vivos con capacidades metabólicas especiales han emergido generando resultados prometedores en procesos de biotransformación. Algunos microorganismos y plantas cuentan con diferentes mecanismos bioquímicos para contrarrestar la toxicidad de los metales pesados. En la presente revisión se abordan dichos mecanismos, se nombran algunas especies de organismos destacadas y se hace un esbozo acerca de algunas aproximaciones de ingeniería genética con el objetivo de mejorar las capacidades biorremediadoras de estas especies.

Palabras clave: Biotecnología, contaminación, genética, microorganismos, plantas metalófitas.

1 Universidad de Boyacá. Departamento de Biología y Microbiología. Grupo de investigación Gestión Ambiental. MSc. en Ciencias Microbiología. Tunja. Colombia.

2 Universidad de Boyacá. Departamento de Biología y Microbiología. Grupo de investigación NúCLEO. MSc. en Ciencias Biológicas. Tunja. Colombia. 


\section{ABSTRACT}

Heavy metals are considered one of the most toxic pollutants in the atmosphere to have harmful effects at the level of the whole food chain, in special $\mathrm{Cd}, \mathrm{Cr}$ and $\mathrm{Hg}$ are relevant because of their persistence and toxicity. At present, there are various types of physicochemical techniques used for the treatment of these substances, which have shown some weaknesses and long-term secondary effects. Therefore, the implementation of other technologies involving living organisms with special metabolic capabilities have generated promising results that have emerged in biotransformation processes. Some microorganisms and plants have different biochemical mechanisms to counteract the toxicity of heavy metals. In this review, these mechanisms have been addressed, some species of outstanding organisms are named and an outline about some genetic engineering approaches with the aim of improving the capabilities of these species bioremediation has been made.

Keywords: Biotechnology, pollution, genetics, microorganisms, metallophytes plants.

\section{INTRODUCCIÓN}

Desde la revolución industrial, los impactos antropogénicos han liberado al ambiente muchos metales pesados peligrosos que son desechos contaminantes muy tóxicos; las actividades asociadas principalmente con procesos de manufactura, disposición de aguas residuales domésticas e industriales y aplicación de fertilizantes fosforados son las principales fuentes de metales en los ecosistemas (Bolan et al, 2014; Wu et al, 2010).

Un metal pesado se define como un elemento que tiene propiedades metálicas como ductibilidad, conductividad, densidad, estabilidad como catión y especificidad a ligando (Garbisu et al, 2003). Bajo la denominación de metales pesados se incluye a un conjunto de 65 elementos de la tabla periódica con un número atómico mayor a 20 y con una alta densidad relativa, mayor o igual a $5 \mathrm{~g} / \mathrm{cm}^{3}$ en su forma elemental. Estos presentan diferentes características fisicoquímicas y biológicas, se encuentran formando complejos como iones libres o participando en reacciones redox que resultan potencialmente tóxicas para los organismos (Marrero et al, 2010; Lucho et al, 2005).

Por otra parte, los metales pesados son imprescindibles para el desarrollo de microorganismos, plantas y animales pues ejercen roles importantes en algunas reacciones bioquímicas y son esenciales para su crecimiento y desarrollo (Nessner y Esposito, 2010). Sin embargo, cuando se presentan en altas concentraciones pueden formar compuestos inespecíficos creando efectos citotóxicos y letales (Nies, 1999; Soto et al, 2010). Es importante anotar que si bien algunos metales no tienen influencia biológica, otros como el cadmio (Cd), el cromo (Cr), y el mercurio $(\mathrm{Hg})$ son tóxicos (Nessner y Esposito, 2010).

La acción tóxica de los metales pesados sobre los seres vivos ocurre a través del bloqueo de las 
actividades biológicas, es decir la inactivación enzimática por la formación de enlaces entre el metal y los grupos sulfhidrilos (-SH) y otros grupos funcionales de las proteínas y enzimas, causando daños irreversibles en los diferentes organismos, desplazando otros iones metálicos o modificando la conformación activa de moléculas biológicas (Garbisu y Alkorta, 2003; Rajendran et al, 2003).

Una vez los metales son emitidos se absorben muy fácilmente a través de las membranas biológicas, por su elevada afinidad química a las proteínas aumentando su bioacumulación, dificultando su degradación y eliminación (Soto et al, 2010). Existen estrategias biológicas en donde microorganismos y plantas pueden inmovilizar o transformar el metal in situ, lo cual puede reducir su biodisponibilidad (Rajendran et al, 2003).

Las estrategias de remediación basadas en procesos microbianos (microremediación) pueden minimizar la toxicidad y la biodisponibilidad de los metales pesados. Dentro de estas técnicas se encuentran la bioestimulación en donde se activa a la población microbiana nativa; la bioaumentación que involucra la introducción artificial de poblaciones viables, la bioacumulación utilizando células vivas y la biosorción mediante biomasa microbiana muerta. Estas técnicas se caracterizan por ser tecnologías de remediación promisorias desde el punto de vista económico y de efectividad (Rajendran et al, 2003).

De otro lado, la fitoremediación es el uso de plantas para remover contaminantes del ambiente. Existen plantas denominadas hiperacumuladoras que pueden absorber grandes cantidades de metales en sus tejidos aéreos como tallos y hojas, lo cual es una ventaja a la hora del postratamiento de metales pesados. Tanto la microremediación como la fitoremediación pueden ser potencializados utilizando tecnologías transgénicas, lo que recibe el nombre de tratamiento simbiótico o rizoremediación que pueden constituirse en una técnica óptima para remover y acumular metales peligrosos (Wu et al, 2010).

El presente documento pretende dar a conocer cuáles son las estrategias bioquímicas desarrolladas por microorganismos y plantas biorremediadoras de metales, destacar ciertas especies utilizadas eficientemente para la remoción de contaminantes como $\mathrm{Cr}$, Cd y Hg por ser estos contaminantes ampliamente difundidos y con mayor afectación en la salud y en el ambiente, además de realizar un esbozo acerca de la utilización de la ingeniería genética para el mejoramiento de los procesos de remediación de este tipo de contaminantes.

\section{MECANISMOS BIOQUÍMICOS DESARROLLADOS POR LOS MICROORGANISMOS PARA EL TRATAMIENTO DE METALES PESADOS}

Los microorganismos juegan un rol vital en la transformación de elementos traza incluidos los metales ya que influencian su biodisponibilidad y remediación, pueden alterar la toxicidad, solubilidad en agua y la movilidad del elemento (Bolan et al, 2014). Los microorganismos modifican la concentración de metales pesados en el ambiente, pues estos cuentan con mecanismos enzimáticos y no enzimáticos para remover metales en solución (Rajendran et al, 2003). La capacidad de remoción de metales por bacterias, microalgas y hongos es superior a la reportada con métodos fisicoquímicos convencionales, también se conoce que la adquisición y remoción de los metales pesados puede ser selectiva teniendo en cuenta la capacidad metabólica de cada especie biorremediadora y el tipo de metal (Zenhg et al, 2008).

Entre las transformaciones enzimáticas de los metales realizadas por microorganismos se incluyen la oxidación, la reducción, la metilación, la demetilación; las cuales pueden dar como resultado 
compuestos poco solubles en agua o bien compuestos volátiles (Marrero et al, 2010). A continuación se describen diferentes mecanismos bioquímicos desarrollados por los microorganismos para transformar o acumular diversos iones metálicos.

\section{Unión a metales, bioacumulación y biosorción}

Los metales se unen a la superficie celular a través de mecanismos que incluyen interacciones electrostáticas, fuerzas de Van de Waals, unión covalente, interacciones redox, precipitación extracelular o la combinación de esos procesos; los grupos cargados negativamente (carboxil, hidroxil y fosforil) de la pared celular bacteriana adsorben los iones metálicos y estos son retenidos (Rajendran et al, 2003).

Cuando los metales se unen a la superficie celular pueden bioacumularse. La bioacumulación es un proceso celular que involucra un sistema de transporte de membrana que internaliza el metal pesado presente en el entorno celular con gasto de energía, este consumo energético se realiza a través de la $\mathrm{H}^{+}$-ATPasa; una vez incorporado el metal pesado al citoplasma este es secuestrado por proteínas ricas en grupos sulfhidrilos llamadas metalotioneinas $(\mathrm{MT})$, fitoquelatinas (FQ) y algunos nuevos péptidos de unión a metales, si se trata de hongos este es compartimentalizado dentro de las vacuolas (Marrero et al, 2010).

Las metalotioneinas (MT's) fueron descubiertas hace 45 años y juegan un rol central en el metabolismo de metales pesados y en el manejo de varias formas de estrés microbiano. Las MT's son proteínas de bajo peso molecular (6-7 KDa) ricas en cisteína, que se dividen en tres clases de acuerdo al contenido de cisteína y a su estructura; la primera clase son las que tienen dominios $\mathrm{Cis}$-Cis, las segundas las que tienen dominios $\mathrm{Cis-} \mathrm{X}$-Cis y las terceras las que tienen dominios $\mathrm{Cis-X-X-Cis} \mathrm{en} \mathrm{donde} \mathrm{X}$ corresponde a cualquier aminoácido. Estas proteínas han sido aisladas de especies bacterianas como Escherichia coli y Pseudomonas putida y los géneros Cyanobacterium sp. y Syneococcus sp. (Rajendran et al, 2003).

Las metalotioneinas juegan un rol fundamental en la interacción microorganismo-metal, cuando el metal se une a ellas se facilita su absorción y transformación, en la actualidad se han encontrado y manipulado genéticamente nuevos péptidos que se unen a metales, estos contienen residuos de histidina o cisteína y muestran afinidad, especificidad y selectividad por ciertos iones de metales (Wu et al, 2010).

Valls et al, 2000, han reportado que la adición de una cepa modificada de la bacteria Ralstonia eutropha con capacidad de secuestrar metales en suelos contaminados; permitió que estos se vuelvan menos disponibles; si bien se conoce que las bacterias pueden ligar metales a sus superficies celulares infortunadamente su capacidad natural de ligar metales es generalmente insuficiente para mitigar significativamente la contaminación producida por estos. Sin embargo estas metodologías pueden implementarse con algunas modificaciones para lograr resultados más eficientes.

Gracias al mecanismo de bioacumulación o unión a metales descrito anteriormente, se ha desarrollado la tecnología de la biosorción, esta utiliza biomasa microbiana activa o inactiva para secuestrar metales, mediante su unión a la superficie celular (Nessner y Esposito, 2010). El proceso ocurre por diversos mecanismos fisicoquímicos como la adsorción o el intercambio iónico y cuando se utiliza biomasa viva, los mecanismos metabólicos de captación también pueden contribuir con el proceso (Cañizares, 2000).

Esta estrategia ha sido aplicada usando biomasa de bacterias, algas, hongos y levaduras generalmente inactivada (Vasudevan et al, 2001). Varios grupos de constituyentes celulares como el grupo acetamido de la quitina, polisacáridos estructurales de los hongos, grupos sulfhidrilos, amino y carboxilo de algunas proteínas, grupos fosfato e hidroxil de 
polisacáridos participan en la biosorción (Vasudevan et al, 2001). Las especies metálicas son efectivamente retenidas al interactuar con los fosfatos, proteínas y lípidos en el citoplasma celular, compitiendo con los iones de sodio, potasio y calcio en los mecanismos biológicos. Las posibilidades de desarrollar una mayor capacidad de absorción dependen del tipo de microorganismo y su etapa de crecimiento (Soto et al, 2010).

La tecnología de biosorción involucra el acomplejamiento superficial y la microprecipitación como alternativas potenciales para el tratamiento actual de los metales, estos son fenómenos ampliamente estudiados en la biorremediación de metales pesados como el $\mathrm{Cd}$ (II) y el $\mathrm{Cr}$ (II). Los microorganismos utilizados como biosorbentes aislados a partir de ecosistemas contaminados, retienen metales pesados a intervalos de tiempo relativamente cortos al entrar en contacto con las disoluciones de los metales, esto minimiza los costos en el proceso de remediación pues no requiere el agregado de nutrientes al sistema porque el microorganismo no necesita un metabolismo activo, además la biomasa es fácilmente extraíble de los sistemas acuosos (Rajendran et al, 2003).

Los biofiltros elaborados con microalgas y bacterias han sido usados para la descontaminación de $\mathrm{Cr}$ y Cd a partir de desechos de metales (Loutseti et al, 2009), la utilización de células inmovilizadas tiene ventajas frente al uso de células libres para el tratamiento y remoción continua de metales, ya que la biomasa inmovilizada en columnas de sorción puede funcionar por ciclos de carga, regeneración y enjuague; mientras que si se usan células libres debido a su pequeño tamaño se dificulta la recuperación de la biomasa del efluente (Gupta et al, 2000).

La biomasa microbiana puede ser inmovilizada en un amplio rango de materiales inertes como silica, poliacrilamida, polimetano y polisulfona que han sido usados en variedad de bioreactores. Ibanez y
Umetsu (2002), demostraron la efectividad en la remoción de $\mathrm{Cr}$ y Co al utilizar perlas de alginato protonado en disoluciones acuosas. Sin embargo, si se considera el uso de células vivas para un sistema de eliminación de metales, la toxicidad de ciertos metales puede conducir a un envenenamiento e inactivación, por lo que el uso de biomasa muerta o sus productos derivados elimina el problema de la toxicidad, provocada por metales disueltos y por las condiciones adversas de operación, además del componente económico de mantenimiento incluyendo el suplemento de nutrientes (Cañizares, 2000).

Por otro lado algunas bacterias del género Pseudomonas sp. han mostrado ser eficientes en la bioacumulación de metales pesados en efluentes industriales contaminados (Ramteke, 2000), este proceso ha ganado importancia en los últimos años debido a su buen rendimiento, bajo costo, especificidad, mínima generación de lodos y fácil reutilización (Ahuja et al, 2001). Así mismo, los hongos han recibido especial atención con relación a la biosorción de metales, particularmente porque la biomasa fúngica se origina como un subproducto de diferentes fermentaciones industriales (Cañizares, 2000). Kim et al, (2003) utilizaron el hongo Trichoderma ressei para analizar las características de adsorción y desorción de Cd y Cu.

\section{Transformación de la valencia del metal}

Dependiendo del estado de oxidación del metal un microorganismo puede realizar dos posibles transformaciones, una corresponde a la movilización del metal, es decir la transformación del estado insoluble inicial que corresponde a una fase sólida a un estado soluble final que se presenta en fase acuosa, este proceso se conoce como lixiviación; la otra transformación es la inmovilización del metal que es un proceso en donde la fase soluble inicial en fase acuosa pasa a un estado insoluble final en fase sólida (Soto et al, 2010). 
La solubilidad y movilidad de los metales depende de su estado de oxidación y de su forma iónica (Bolan et al, 2014). Los metales de diferentes valencias varían en su toxicidad; cuando se excretan enzimas redox especiales, los microorganismos pueden transformar el metal a formas menos tóxicas. Las reacciones redox se agrupan en dos categorías, las asimilatorias y las desasimilatorias; en las reacciones asimilatorias el metal está involucrado en las reacciones metabólicas del organismo actuando como aceptor final de los electrones; mientras que en las reacciones desasimilatorias no se conoce el rol del metal en el metabolismo del organismo e indirectamente inicia las reacciones redox (Bolan et al, 2014).

Según Garbisu et al, (2003) los microorganismos pueden detoxificar metales por transformación en la valencia y reduciendo enzimáticamente un metal en procesos metabólicos que no están relacionados con la asimilación del metal; en este caso varias bacterias acoplan la oxidación de ácidos orgánicos simples, alcoholes, hidrógeno o compuestos aromáticos con la reducción de Fe (III) o Mn (IV).

La detoxificación por reducción requiere que el potencial redox del metal pesado se encuentre entre el potencial redox de la pareja $\mathrm{H}_{2} / \mathrm{H}_{+}(-421 \mathrm{mV})$ y el potencial redox de la pareja $\mathrm{O}_{2} / \mathrm{H}_{2}(+808 \mathrm{mV})$ que constituye el intervalo redox fisiológico para muchas células aerobias, de esta manera el Hg (II) (+430 mV) puede ser reducido por la célula pero el Cd (II) debido a su potencial de reducción (-824 mV) no puede ser transformado. Si un metal no puede ser reducido por vías celulares o su reducción no es conveniente, entonces el metal puede ser acomplejado o transportado al exterior celular, o pueden suceder ambos eventos (Marrero et al, 2010).

La oxidación de Cr (III) a Cr (VI) puede incrementar la movilidad y disponibilidad del metal, mediada por procesos bióticos y abióticos (Choppala et al, 2013). Varias bacterias han sido reportadas por reducir cromo hexavalente que es tóxico y mutagénico a su forma trivalente que es menos tóxica y menos soluble (Garbisu et al, 2003); la reducción abiótica se da cuando está disponible una fuente de electrones como el Fe (II) y el proceso microbiano o reducción biótica puede darse en condiciones aeróbicas o anaeróbicas y solo ocurre en presencia de materia orgánica como fuente de electrones (Bolan et al, 2014).

La reducción del cromo VI es llevada a cabo por la enzima cromato reductasa que se encuentra muy bien caracterizada en Pseudomonas ambigua, además se conoce que otras reductasas celulares pueden también llevar a cabo la reducción del cromato como la DT-diaforasa, aldehído oxidasa, citocromo P450 y algunas nitroreductasas (Marrero et al, 2010). Este mecanismo también se observa en bacterias resistentes a $\mathrm{Hg}$ en las cuales se produce la proteína liasa organomercurial (MerB), que transforma el metilmercurio $\left(\mathrm{CH}_{3} \mathrm{Hg}^{+}\right)$a $\mathrm{Hg}(\mathrm{II})$ que es cien veces menos tóxico (Wu et al, 2010).

\section{Biometilación y mecanismo de volatilización}

La metilación es un mecanismo biológico para la remoción de metales y metaloides, este ocurre cuando los metales son convertidos a derivados metilados que posteriormente son removidos por volatilización. Es un proceso dominante en suelos y en ambientes acuáticos y resulta en la detoxificación del metal, mientras que los derivados metilados pueden ser excretados rápidamente desde las células y frecuentemente se volatilizan o se transforman a formas menos tóxicas (Bolan et al, 2014).

Los microorganismos en suelos y sedimentos actúan como agentes metiladores ya que la materia orgánica provee una fuente de grupos metilo para que se dé el proceso. En la metilación de mercurio los iones de Hg (II) son metilados por transferencia no enzimática de grupos metil desde la metilcobalamina y es transformado ya sea a monometil o dimetil mercurio que son formas altamente tóxicas pero muy móviles 
(Ullrich et al, 2001), este proceso es controlado por fracciones de bajo peso molecular de ácidos fúlvicos en los suelos y puede ocurrir tanto en condiciones aeróbicas como anaeróbicas, pero se conoce que la mayor proporción de mercurio metilado se genera bajo estas últimas condiciones (Loseto et al, 2004).

Cuando se transforman iones de metales a su estado volátil, los microorganismos escapan del posible efecto negativo de los iones metálicos unidos a ellos, sin embargo, esta capacidad es factible solo para algunos metales como el $\mathrm{Hg}$, para la mayoría de los demás metales que no tienen fase volátil esta ruta no es funcional (Wu et al, 2010).

En la actualidad la forma como los microorganismos transforman el $\mathrm{Hg}$ es relativamente clara; en las células de bacterias resistentes a este metal se produce la enzima citoplásmica mercurio reductasa (MerA) que es la enzima que reduce $\mathrm{Hg}$ (II) a $\mathrm{Hg}(0)$ que es la forma volátil y menos tóxica del metal en la presencia de donadores de electrones (junto a la enzima organomercurio liasa en el caso de los compuestos organomercuriales) (Wu et al, 2010). La enzima (Mer A) ha sido la enzima más estudiada debido a la importancia de ese elemento como contaminante ambiental y al papel primordial de los microorganismos dentro del ciclo biogeoquímico del mercurio (Borremans et al, 2002), la bacteria reductora desasimilatoria Shewanella oneidensis ha mostrado esta capacidad (Wiatrowski et al, 2006).

La meta de la remediación microbiana de suelos o sedimentos contaminados con metales pesados es inmovilizar el metal in situ para reducir la biodisponibilidad, su movilidad o remover el metal del suelo (Rajendran et al, 2003). Sin embargo, la única estrategia in situ que emplea microorganismos y remueve metales es la reducción microbiana del ion mercurio $\mathrm{Hg}$ (II) a un mercurio metálico volátil Hg (0) (Hobman y Brown, 1997), en este caso, el mercurio volátil reducido puede fluir hacia afuera del área contaminada y ser diluido en la atmósfera (Lovley y Lloyd, 2000), infortunadamente los microorganismos no volatilizan rápidamente muchos otros metales tóxicos.

\section{Mecanismo de precipitación química extracelular}

Los microorganismos secretan productos metabólicos de tipo inorgánico como iones sulfatos, carbonatos o fosfatos que pueden precipitar iones metálicos tóxicos como una forma de detoxificación no enzimática. En la naturaleza los microorganismos inmovilizan metales a través de la precipitación extracelular (Rajendran et al, 2003).

Un buen número de sustancias ligadoras de metales son excretadas por los microorganismos, éstas varían desde ácidos orgánicos simples, alcoholes, grandes polisacáridos o ácidos húmicos y fúlvicos. Recientes estudios han encontrado que los grupos carboxil del peptidoglicano son el principal lugar de unión de cationes en la pared celular de bacterias gram positivas, mientras que en gram negativas es el grupo fostato y en los hongos sería la quitina, sin importar que la precipitación sea en la superficie externa de la pared celular o lejos de ella, siendo un mecanismo exitoso para mantener los iones tóxicos fuera del citoplasma (Wu et al, 2010).

Muchos microorganismos producen y excretan sideróforos que son moléculas acomplejantes de hierro, muchas de las cuales tienen alta afinidad por los metales pesados, en Pseudomonas aeruginosa y Alcaligenes eutrophus la síntesis de sideróforos está inducida por metales pesados en presencia de altas concentraciones de hierro (Gilis et al, 1996).

Por otra parte, algunas bacterias son capaces de disminuir la solubilidad de los metales y su movilidad disminuyendo su fitotoxicidad (Lasat, 2000), quizá esta característica se atribuye o se relaciona con la producción de biosurfactantes. Juwarkar et al, (2007) aplicaron biosurfactantes producidos por Pseudomonas aeruginosa para la remediación de suelos contaminados con $\mathrm{Cd}$ y $\mathrm{Pb}$ con buenos resultados. Igualmente 
los ramnolípidos, un tipo de biosurfactantes producidos por $P$. aeruginosa muestran especificidad por ciertos metales tales como Cd (Rajendran et al, 2003).

Otra de las aplicaciones biotecnológicas más importantes en la interacción metal-microorganismo es la biolixiviación (Rajendran et al, 2003), que consiste en la recuperación de metales por parte de algunos microorganismos capaces de disolverlos desde el ambiente (Nessner y Esposito, 2010). La bioprecipitación de bacterias reductoras de sulfato que convierten sulfato a sulfuro de hidrógeno que a su vez, reacciona con metales pesados para formar sulfuros de metal insoluble como el sulfuro de cadmio ha sido reportada en algunas bacterias (Garbisu et al, 2003).

\section{Mecanismo simbiótico}

El mecanismo simbiótico de biorremediación hace relación a la posibilidad de utilizar plantas combinadas con algunos microorganismos para aumentar la eficiencia de la extracción de contaminantes, tal técnica recibe el nombre de rizorremediación (Jing et al, 2007). Chaudhry et al, (2005) reportaron que el uso de esa asociación benéfica es útil, ya que los microorganismos aumentan la disponibilidad de los compuestos contaminantes y las plantas ayudan en la extracción y remoción de tales sustancias. Se conoce que algunas bacterias pueden estimular el crecimiento y la toma de fósforo y metales por parte de plantas hiperacumuladoras como Sedum alfredii (Li et al, 2010).

Una desventaja de la microrremediación es que los metales absorbidos permanecen en el suelo, mientras que el mecanismo simbiótico puede ser más efectivo al combinar la microrremediación con la fitoremediación, esto debido a que la relación simbiótica que puede existir entre plantas y bacterias, es un mecanismo positivo para todos los organismos implicados, por una parte las plantas suministran nutrientes a los microorganismos para su crecimiento y se sugiere que las bacterias apoyan el crecimiento de la raíz incrementando la capacidad de acumulación del metal por parte de las plantas (Wu et al, 2010).

El suelo puede acidificarse más eficientemente lo que permite una mejor solubilidad, movilidad y biodisponibilidad de los metales pesados; después de que los metales están activados, los iones pueden acumularse en las raíces de las plantas, ser transportados por el xilema y detoxificados por quelación, compartimentalización vacuolar y volatilización, pero por otra parte pueden acumularse en la rizósfera o los nódulos y también ser remediados por procesos microbianos (Wu et al, 2010).

No obstante, se conoce poco acerca del sinergismo entre plantas y microorganismos y los factores que generan las respuestas, se sabe que a nivel de bacterias existe una clase de comunicación celular denominada Quorum sensing que es un mecanismo usado para regular la expresión de los genes en respuesta a fluctuaciones en la densidad celular y que es eficiente para regular muchas actividades fisiológicas (Miller y Bassler, 2001).

\section{MICROORGANISMOS IMPLICADOS EN LOS PROCESOS DE BIORREMEDIACIÓN DE METALES PESADOS $(\mathrm{Cd}, \mathrm{Cr}, \mathrm{Hg})$}

Los metales son compuestos recalcitrantes, persistentes y biomagnificables (Cañizares, 2000). Se conoce la capacidad de transformación de metales pesados como el $\mathrm{Cr}$, el $\mathrm{Cd}$ y el $\mathrm{Hg}$ por parte de bacterias y ciertas especies de hongos (Tabla 1.).

Se conoce que los hongos de micorriza arbuscular (HMA) pueden ser usados en procesos de fitorremediación (Khan, 2006). Se ha reportado que varias especies de HMA y varios aislamientos de una misma especie pueden diferir en su sensibilidad a los metales pesados (Khade y Adholeya, 2007). Los hongos micorrísicos reducen la toxicidad del metal 
Tabla 1. Algunos microorganismos implicados en la biorremediación de metales pesados.

\begin{tabular}{|c|c|c|}
\hline Microorganismo & Metal & Referencia \\
\hline $\begin{array}{c}\text { Cunninghamella echinulata, Fusarium oxysporum, } \\
\text { Rhizopus stolonifer, Thrichoderma viride }\end{array}$ & $\mathrm{Cd}$ & Babich y Stotzky, 1977 \\
\hline Staphylococcus xylosus, S. carnosus & $\mathrm{Cd}$ & Samuelson et al, 2000 \\
\hline Trichoderma reesei & $\mathrm{Cd}$ & Kim et al, 2003 \\
\hline Pseudomonas aeruginosa & $\mathrm{Cd}$ & Juwarkar et al,2007 \\
\hline $\begin{array}{c}\text { Deinococcus radiodurans, Thermus thermophilus, } \\
\text { Acidiphlium angustum, Flavobacterium aquatile y } \\
\text { Flavobacterium hibernum }\end{array}$ & $\mathrm{Cd}$ & Ginn y Fein ,2008 \\
\hline Fusarium oxysporum & $\mathrm{Cd}$ & Akpor y Muchie, 2010 \\
\hline $\begin{array}{c}\text { Vibrio harveyi, Enterobacter cloacae, Rhodobium } \\
\text { marinum, Rhodobacter sphaeroides }\end{array}$ & $\mathrm{Cd}$ & Dash et al, 2013 \\
\hline Glomus sp, Gigaspora sp, Acaulospora sp. & $\mathrm{Cd}$ & Sambandan et al, 1992 \\
\hline Pseudochrobactrum saccharolyticum & $\mathrm{Cr}(\mathrm{VI})$ & Long et al, 2013 \\
\hline Enterobacter cloacae & $\mathrm{Cr}(\mathrm{VI})$ & $\begin{array}{l}\text { Campos et al, 1995; Wang et } \\
\text { al, 1989, Kavamura y Esposito, } \\
\text { 2010) }\end{array}$ \\
\hline $\begin{array}{c}\text { Pseudomonas sp, Micrococcus sp, Bacillus } \\
\text { sp, Achromobacter sp, Microbacterium } \\
\text { sp,Arthrobacter sp, y Corynebacterium sp, Voge- } \\
\text { sella indigofera }\end{array}$ & $\mathrm{Cr}(\mathrm{VI})$ & Dhal et al, 2013 \\
\hline Pseudomonas ambígua, E.coli, C. metallidurans & $\mathrm{Cr}$ & Borremans et al, 2002 \\
\hline Bacillus sp. & $\mathrm{Cd}, \mathrm{Cr}$ y $\mathrm{Hg}$ & Cañizares, 2000 \\
\hline $\begin{array}{c}\text { Staphylococcus aureus, Bacillus subtilis, Listeria } \\
\text { sp, E.coli, A. eutrophus, P. putida. }\end{array}$ & $\mathrm{Cr}$ y Cd & Roane y Pepper, 2000 \\
\hline $\begin{array}{c}\text { Aeromonas sp, Staphylococcus aureus, Lacto- } \\
\text { bacillus sp, Micrococcus sp, Bacillus sp, Bacillus } \\
\text { megaterium, Acinetobacter sp, Pseudomonas } \\
\text { aeruginosa, Escherichia coli }\end{array}$ & $\mathrm{Cr}$ y Cd & Ali et al, 2009 \\
\hline Geobacillus thermodenitrificans & $\mathrm{Cr}^{+3}$ y $\mathrm{Cd}^{+2}$ & Chatterjee et al, 2010 \\
\hline Shewanella oneidensis & $\mathrm{Hg}(I I)$ & Wiatrowski et al, 2006 \\
\hline
\end{tabular}




\begin{tabular}{|c|c|c|}
\hline Chlamydomonas reinhardtii & $\mathrm{Hg}(I I)$ & Bayramoglu y Arica, 2008 \\
\hline Trichoderma harzianum & $\mathrm{Hg}(I I)$ & Raspanti et al, 2009 \\
\hline Enterobacter sp., Bacillus cereus & $\mathrm{Hg}(I I)$ & Sinha et al, 2012 \\
\hline Pseudomonas sp., Psychrobacter sp. & $\begin{array}{l}\text { Hg orgánico e } \\
\text { inorgánico }\end{array}$ & Pepi et al, 2011 \\
\hline Pseudomonas balearica & $\begin{array}{c}\mathrm{Me} \mathrm{Hg} \\
\text { (metil mercurio) }\end{array}$ & Lee et al, 2011 \\
\hline Pseudomonas putida V1 & $\begin{array}{c}\text { Me Hg } \\
\text { (metil mercurio) }\end{array}$ & Cabral et al, 2012 \\
\hline $\begin{array}{c}\text { Pseudomonas fluorescens, Enterobacter cloacae, } \\
\text { Citrobacter braakii, Alcaligenes faecalis }\end{array}$ & $\begin{array}{c}\text { Me Hg } \\
\text { (metil mercurio) }\end{array}$ & Adelaja y Keenan, 2012 \\
\hline
\end{tabular}

para su planta hospedera uniendo los iones a su pared celular o rodeándolos con polisacáridos, existen varios sitios de unión a metales en las células de hongos micorríticos similares a las metalotioninas que tienen alto contenido de cisteína y quizá gránulos de polifosfatos (Rajendran et al, 2003). Zimmer et al, (2009) evaluaron el efecto de la inoculación dual de hongos ectomicorriticos y las bacterias $\mathrm{Mi}$ crococcus luteus y Sphingomonas sp. sobre el crecimiento de plantas de sauce (Salix sp.) en suelos contaminados con metales encontrando que estas asociaciones tienen gran potencial biorremediador.

\section{FITORREMEDIACIÓN}

Los métodos tradicionales de remoción de metales pesados muestran limitaciones a largo plazo, debido a los altos costos, gran cantidad de sustancias químicas aplicadas, continuo mantenimiento, además de residuos secundarios y lixiviados (Prasad y Freitas, 2003; Rai, 2008). En general, los métodos físicos y químicos afectan las propiedades del suelo y alteran la microflora, creando posibles problemas de contaminación secundaria (Ali et al, 2013). Por lo tanto se requieren nuevos estudios en ésta área, donde se involucren técnicas de reparación favorables al medio ambiente, que incluyan tecnologías limpias, eficientes y económicas (Lone et al, 2008).

El uso de plantas vasculares para acumular metales pesados se ha expandido rápidamente por diferentes países, la utilización de especies vegetales para trasformar y remover contaminantes del suelo y el agua, conocida como fitoremediación, ha ganado una alta aceptación desde la última década como un tipo de tecnología limpia, que utiliza los organismos naturales y preserva el estado natural del medio ambiente (Salt et al, 1995; Prasad y Freitas, 2003; Kavamura y Esposito, 2010; Paisio, 2012; Swain et al, 2014; Maiti et al, 2004).

El proceso de fitorremediación depende del grado de contaminación, la disponibilidad del contaminante así como de la interacción de la planta con su hábitat (suelo y microorganismos) (Cunningham y Ow, 1995; Saeth, 2012.). Es una tecnología que puede aplicarse in situ para tratar una gran variedad de contaminantes, gracias a la capacidad de absorción de las raíces de las plantas (Akpor y 
Muchie, 2010; Carrión et al, 2012). En el caso de metales pesados, luego de que estos son absorbidos por las plantas, pueden ser extraídos de la biomasa cosechada y ser reciclados (Paz-Ferreiro et al, 2014).

Diferentes investigaciones evidencian el potencial de la fitoremediación para remover, reducir, transformar, mineralizar, degradar, volatilizar o estabilizar diferentes tipos de contaminantes presentes en suelo, aire, agua o sedimentos tales como: metales pesados, metales radioactivos, compuestos orgánicos y compuestos derivados del petróleo (Maiti et al, 2004; Chaney et al, 2007; Padmavathiamma y Li, 2007; Lone et al, 2014; Wu et al, 2010; Paz-Ferreiro et al, 2014; Swain et al, 2014). Para la implementación de estas fitotecnologías, se requiere analizar criterios como la tolerancia y bioacumulación del metal por parte de la planta; así como variables que incluyen la concentración del metal, el pH, el contenido de nutrientes y la materia orgánica disponible (Garbisu y Alkorta 2003; Li et al, 2003; Solisio et al, 2006; Wu et al, 2010; Paz-Ferreiro et al, 2014).

\section{Plantas metalófitas o hiperacumuladoras}

Una planta metalófita o hiperacumuladora es una planta capaz de crecer en el suelo o agua con grandes concentraciones de metales pesados y se caracterizan por extraer el metal a través de sus raíces y concentrarlo hasta niveles extremadamente altos en sus tejidos (Chaney et al, 2007). Estas plantas presentan un rápido crecimiento, amplios rangos de adaptación climática y la capacidad de absorber grandes volúmenes de agua (en relación con otras especies), lo que les permite manejar grandes cantidades de contaminantes disueltos, así como limitar la cantidad de agua que escapa más allá de la zona contaminada y que limita la dispersión de la contaminación (Maiti et al, 2004; Kavamura y Esposito, 2010).

Las metalófitas son plantas que pueden acumular metales de 100 a 500 veces más que otras especies, alcanzando niveles de remoción hasta del
100\% (Chaney et al, 2007). Más de 400 especies vegetales han sido identificadas como hiperacumuladoras, incluidas 300 especies que acumulan $\mathrm{Ni}$ y algunas que tienen la capacidad de acumular $\mathrm{Cd}, \mathrm{Cu}$, $\mathrm{Pb}$ y Zn (Li et al, 2003, Ücüncü et al., 2013). Varios estudios indican que este tipo de vegetación puede almacenar en promedio $100 \mu \mathrm{g} / \mathrm{g}$ (0.01\% peso seco) de Cd y As; $1000 \mu \mathrm{g} / \mathrm{g}$ (0.1\% peso seco) de

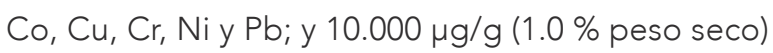
de Mn (McGrath et al, 2001; Padmavathiamma y Li, 2007; Paz-Fereira et al, 2014).

El desarrollo de adaptaciones fisiológicas y bioquímicas por parte de las plantas incluyen el control en la acumulación del contaminante en las raíces y la traslocación de éste a los diferentes órganos vegetativos (McGrath et al, 2001; Padmavathiamma y Li, 2007; Ücüncü et al, 2013). Estos procesos de bioacumulación permiten transformar los contaminantes en productos menos tóxicos o no tóxicos, minimizando su exposición en el ambiente (Favas et al, 2012; Dos Santos y Lenzi, 2000; Mane et al, 2011).

Las plantas pueden inmovilizar los metales en sus vacuolas para evitar la translocación a la parte aérea, siendo consideradas como el lugar de mayor acumulación de metales pesados en células vegetales. La compartimentalización de las vacuolas es efectiva controlando la distribución y concentración de iones de metales, debido a que las otras partes de la célula no tienen acceso a los iones metálicos peligrosos y de esa forma la planta no se afecta (Wu et al, 2010).

La habilidad de acumular metales pesados varía significativamente entre especies, cada una desarrolla diferentes mecanismos para transformar los iones, según sus características morfológicas, fisiológicas y genéticas (Saleth, 2012; Kavamura y Esposito, 2010; Akpor y Muchie, 2010; Borker et al, 2013; Swain et al, 2014). Numerosas especies fitorremediadoras se encuentran taxonómicamente dentro de 
Tabla 2. Características de las principales técnicas de fitoremediación.

\begin{tabular}{|c|c|}
\hline Técnica & Descripción \\
\hline Fitoextracción & $\begin{array}{l}\text { Es la absorción del contaminante por la raíz el cual es almacenado y acumulado } \\
\text { dentro de la biomasa. Incluye el uso de plantas hiperacumuladoras para remover } \\
\text { contaminantes del suelo; el material acumulado en la planta puede disponerse } \\
\text { o quemarse para recuperar el metal pesado. Es una estrategia que depende } \\
\text { de la habilidad natural de algunas plantas de acumular, traslocar y resistir altas } \\
\text { cantidades de metales durante todo su ciclo de crecimiento. }\end{array}$ \\
\hline Fitofiltración & $\begin{array}{l}\text { Secuestro y captura de contaminantes por plantas acuáticas a través de las raíces } \\
\text { de la planta o algunas semillas, se usa principalmente para remover metales } \\
\text { pesados de aguas contaminadas. }\end{array}$ \\
\hline Fitoestabilización & $\begin{array}{l}\text { Durante este proceso las raíces de las plantas absorben los contaminantes del } \\
\text { suelo y lo almacenan en la rizósfera, pueden incorporarlo a la lignina o en el } \\
\text { humus disminuyendo la posibilidad de contaminación. Esto permite la limitación } \\
\text { de la movilidad y biodisponibilidad de contaminantes por mecanismos de } \\
\text { prevención por migración e inmovilización. }\end{array}$ \\
\hline Fitovolatilización & $\begin{array}{l}\text { Conversión de contaminantes a partículas volátiles, se da cuando algunos de los } \\
\text { elementos de los grupos II, Vy VI de la tabla periódica como el Hg son absorbidos } \\
\text { por la raíz, convertidos a formas menos tóxicas y liberados al exterior a través del } \\
\text { follaje. Al convertir los iones metálicos a su estado volátil, algunas especies de } \\
\text { plantas evitan el daño causado por la acumulación duradera de metales pesados. }\end{array}$ \\
\hline Fitodegradación & $\begin{array}{l}\text { Degradación o mineralización de contaminantes orgánicos gracias a la actividad } \\
\text { enzimática específica de la planta, puede utilizar asociaciones de microorganismos } \\
\text { para degradar contaminantes orgánicos. }\end{array}$ \\
\hline Rizodegradación & Degradación de xenobióticos orgánicos en la rizósfera de la planta. \\
\hline Rizofiltración & $\begin{array}{l}\text { Mecanismo en el que se usan plantas terrestres para absorber contaminantes } \\
\text { precipitados y concentrados en un sistema acuoso. }\end{array}$ \\
\hline Fitodesalinización & Remoción del exceso de sales de suelos salinos por halófitos. \\
\hline Fitoestimulación & $\begin{array}{l}\text { Mecanismo en donde la raíz en crecimiento promueve el desarrollo de } \\
\text { microorganismos rizosféricos capaces de degradar el contaminante, usando los } \\
\text { exudados radiculares como fuente de carbono. }\end{array}$ \\
\hline
\end{tabular}

Tomado de: Salt et al, 1995; Navari-izzo y Quartaccim; 2001; Garbisu et al, 2003; Wu et al, 2010; Buta et al, 2014; Paz- Ferreira et al, 2014 modificado por los autores. 
los órdenes Brassicales, Asterales, Solanales, Poales, Malpighiales, Fabales, Caryophyllales y Rosales (Paz-Ferrerira et al, 2014). La familia Brassicaceae es de especial interés, ya que incluye plantas hiperacumuladoras que no son palatables, lo que puede reducir los procesos de bioacumulación de metales en la cadena alimenticia durante los procesos de fitoextracción (Navari-izzo y Quartaccim, 2001).

Las plantas hiperacumuladoras han desarrollado sus propios mecanismos para protegerse frente al estrés por metales. En la Tabla 2 se evidencian las características más relevantes de cada una de las técnicas de fitoremediación.

\section{Mecanismos bioquímicos de \\ fitorremediación de metales pesados}

\section{Metal-proteínas o metalotioneinas}

Según Rascio y Navari-Izzob (2011) las plantas hiperacumuladoras presentan mecanismos bioquímicos para el transporte y acumulación de metales pesados, los cuales se realizan gracias a proteínas transportadoras de las células que se unen y trasladan el ión desde el espacio extracelular hacia el interior de las células. En la planta este proceso se da fundamentalmente en la savia del xilema desde la raíz hasta las hojas, con la participación de ligandos como citrato, nicotilamina, histidina y asparagina, de esta forma los metales llegan al apoplasto de las hojas donde son eliminados o trasformados por las células foliares.

Algunos mecanismos desarrollados por las plantas expuestas a metales pesados involucran proteínas capaces de hacer conexión con los metales, formando estructuras bioquímicas complejas llamadas metal-proteínas o metalotioneinas; sin embargo, estos complejos no son exactamente proteínas, son péptidos. Otras proteínas con capacidad de unirse a metales, son empleadas en el almacenamiento de estos, junto con proteínas integradas en canales transmembranales (Maiti et al, 2004). En el estudio realizado por Wu et al, (2010) se indica que los metales pesados que mejor inducen la síntesis de metaltioneinas son $\mathrm{Cd}, \mathrm{Ag}, \mathrm{Bi}, \mathrm{Pb}, \mathrm{Zn}, \mathrm{Cu}, \mathrm{Hg}$ y $\mathrm{Au}$.

Las metalotioneinas son responsables de la regulación interna de micronutrientes esenciales como el Zn o el Cu y además permiten la protección de la célula ante efectos tóxicos debido a la elevada concentración de iones y metales pesados como $\mathrm{Cd}, \mathrm{Hg}$, entre otros. Este grupo de moléculas ha sido empíricamente clasificado en tres clases: Clase I, incluye todas las metalotioneinas que tienen los residuos de cisteína son localizados en posición similar a la que se presenta en plantas y algunos mamíferos, no tienen aminoácidos aromáticos o histidinas; la Clase II originalmente proviene de las levaduras como Candida albicans o cianobacterias y la Clase III son polipeptidos atípicos compuestos por unidades de glutamil-cisteina (Maiti et al, 2004).

Las fitoquelatinas (FQ) son tipos de metalotioneinas clase III y son sintetizadas enzimáticamente, a diferencia de metalotioneinas clase I y clase II que son codificadas genéticamente. La tolerancia de las plantas a los metales también se relaciona con la producción de estos péptidos que secuestran los metales, uniéndose a ellos y protegiendo a las enzimas sensibles ( $\mathrm{Ja}$ nuary et al, 2008; Maiti et al, 2004; Nessner et al, 2010).

La aparición de los FQ se induce por la exposición de organismos autotróficos, incluidos plantas monocotiledóneas, gimnoespermas y algas (Kneer y Zenk, 1992). En algunas especies vegetales las FO son inducidas por metales como $\mathrm{Cd}, \mathrm{Ag}, \mathrm{Bi}, \mathrm{Pb}, \mathrm{Zn}$, $\mathrm{Cu}, \mathrm{Hg}$ y $\mathrm{Au}$; algunos estudios demuestran que la biosíntesis de $\mathrm{FQ}$ procede de la activación metálica de enzimas que constituyen el sustrato glutatión, estas enzimas glutamicisteina transpeptidasa son conocidas como FQ sintetasas (Maiti et al, 2004).

La regulación de la actividad enzimática de la FQ sintetasa se basa en dos modelos, el primero establece que el dominio $\mathrm{N}$ - terminal posee un sitio activo 
que cataliza la acción de la FO a través de su activación por interacciones entre metales pesados con residuos de histidina y cisteína en ese dominio. Diferentes mutaciones en la región C-terminal no destruyen las actividades enzimáticas a través de la conexión con metales, esto aparece porque la FQ sintetasa es expresada continuamente y los niveles de la enzima y el RNAm no cambian sobre la exposición a los metales pesados, este resultado sugiere que no existe regulación a nivel de transcripción (Cobbeett, 2000).

Este mecanismo está probado en el estudio realizado por Salt et al, (1995) en donde se evidenció la detoxificación y tolerancia al Cd; el cadmio induce la síntesis de fitoquelatinas (FQ) y forma una molécula $\mathrm{Cd}-\mathrm{FQ}$ que es transferida a la vacuola por medio de un transportador antiportador $\mathrm{Cd} / \mathrm{H}+$ dependiente de Adenosin trifosfato (ATP). Este proceso se ve influenciado por factores externos como la presión osmótica de la raíz, donde una gran concentración de metales en el exterior favorecerá un mayor desplazamiento hacia su interior; por otra parte las altas temperaturas incrementan la tasa de evapotranspiración y eso conduce a que se dé un mayor movimiento del agua de la raíz a la parte aérea y con ello de los metales (Baghour et al, 2001).

\section{Quelación}

Bricker et al, (2001) reportaron que la quelación es considerada como una herramienta para la extracción de metales pesados en las plantas. Este proceso juega un rol esencial no solo en la acumulación y transporte de metales pesados, sino también en la fase de detoxificación. Usualmente los quelantes contienen ligandos (como la histidina y citrato) que pueden unirse a iones metálicos; cuando esto ocurre, los metales combinados pierden su carga y son incapaces de reaccionar con otras sustancias haciendo que el daño a la célula disminuya (Wu et al, 2010).

Ciertos agentes quelantes facilitan la toma del metal del suelo a la planta, a través del tonoplasto y las vacuolas protegiendo la actividad celular de la toxicidad de metales pesados. Este método, ampliamente utilizado demuestra la capacidad de las plantas para tolerar altos niveles de metales pesados sin causar un efecto deletéreo sobre sus funciones metabólicas (Maiti, 2004). Dentro de los agentes quelantes más reconocidos están varios ácidos orgánicos (ácido málico y ácido cítrico) que han sido identificados como agentes positivos para acelerar la absorción de metales pesados por la raíz, esos mecanismos son aún más notables en el transporte raíz-brote (Maiti, 2004).

Por otra parte, se conoce que agentes como el EDTA influencian la biodisponibilidad de metales pesados en suelos contaminados, promoviendo la acumulación de Cd y Cr (January et al, 2008). El EDTA es un agente eficiente, debido a que promueve la translocación de metales pesados desde las raíces a las partes verdes de la planta. Un resultado de la quelación es la reducción de la toxicidad de la biomasa en la planta, disminuyendo la acumulación del metal (Kukier y Chaney, 2000). Sin embargo, el EDTA es poco biodegradable en los suelos (Luo et al, 2006) y puede disminuir la biomasa vegetal, destruir las barreras fisiológicas de la raíz o inactivar las proteínas transportadoras hasta el punto que sus beneficios en movilizar y translocar metales son minimizados.

\section{ESPECIES DE PLANTAS IMPLICADAS EN LOS PROCESOS DE FITORREMEDIACIÓN}

Algunas especies vegetales pueden remover altas concentraciones de metales a partir de suelo y agua contaminados (Tabla 3), se ha comprobado que dicha exposición genera incremento de la biomasa vegetal y aumento de la longitud de las raíces; además se han evidenciado altas concentraciones de metales a nivel de tallos, hojas y raíces producto de la fitoacumulación (Li et al, 2003). En diversas 
investigaciones se demuestra el rol de la rizósfera en los procesos de hiperacumulación de metales, indicando que los ligandos orgánicos exudados por las raíces contribuyen a dicho proceso. Por otra parte, se ha concluido que la capacidad de fitoextracción de metales se presenta principalmente en sistemas monometálicos, los cuales son mucho más efectivos que los sistemas multimetálicos (Buta et al, 2014).

Se conoce que diferentes tipos de plantas hidrófitas pueden ser usadas para remoción de metales pesados, debido a su capacidad de alcanzar altas tasas de reproducción y crecimiento (Zhu et al, 1999; Dos Santos y Lenzi, 2000; Jafari, 2010; Mane et al, 2010). Estas plantas pueden reducir las concentraciones de metales pesados en aguas contaminadas por las actividades mineras, mientras que exhiben pocos signos de toxicidad, de esta forma presentan potencial aplicación en el tratamiento de aguas residuales industriales y comerciales (Carrión et al, 2012; Saleh, 2012; Sood et al, 2012; Borker et al, 2013; Swain et al, 2014).

La respuesta de las plantas al estrés por los metales pesados puede variar dependiendo del metal y su concentración, generalmente la concentración de pigmentos fotosintéticos revela una alta tolerancia a los metales pesados (Weerasinghe et al, 2008; Kumar et al, 2012; Bharti y Banerjee, 2013; Buta et al, 2014). Esto indica que la tolerancia de los metales por las plantas es atribuida principalmente a la acumulación en los tejidos, donde se usa el término de partes "no funcionales" como indicador de tolerancia ante condiciones naturales adversas (Zhu et al, 1999).

\section{INGENIERÍA GENÉTICA Y BIORREMEDIACIÓN}

\section{Microorganismos genéticamente modificados}

Recientes avances en el campo de la biología molecular han contribuido al estudio de la dinámica de las comunidades microbianas presentes en el ambiente sin la parcialidad que incluye el cultivo de microorganismos; algunos métodos moleculares utilizados para el rastreo o monitoreo de bacterias utilizadas en biorremediación son técnicas basadas en el estudio del ácido desoxiribonucleico (ADN) global de las comunidades, destacándose el uso de sondas o amplificación por Reacción en Cadena de la Polimerasa (PCR) de genes catabólicos responsables de procesos de biorremediación (Rajendran et al, 2003).

Una herramienta molecular alternativa es el uso de biomarcadores para la identificación de bacterias específicas en la naturaleza. Un biomarcador se define como una secuencia de ADN introducida en un organismo que le confiere un genotipo o fenotipo distintivo que permite monitorearlo en un ambiente dado, en la actualidad se han desarrollado varios tipos de biomarcadores para monitorear la eficacia de la biorremediación por parte de inoculantes microbianos (Jansson et al, 2000).

Otros métodos moleculares que pueden ser utilizados en un proceso de biorremediación in situ y que han emergido como técnicas poderosas para monitorear los cambios en la diversidad incluyen la hibridación fluorescente in situ (FISH) con sondas de RNAr marcadas (Hahn et al, 1992), PCR in situ (Hodson et al, 1995), los polimorfismos de la longitud de los fragmentos de restricción (T-RFLP) (Liu et al, 1997; Garbisu et al, 2003) y la electroforesis en gradiente denaturante (DGGE) de fragmentos del gen 16SrDNA (Muyzer et al, 1993). En suelos contaminados con metales pesados usando DGGE se logró encontrar bacterias pertenecientes a los géneros: Arthrobacter, Bacillus, Brevibacterium, Brochothrix, Comamonas, Cytophaga, Deinococcus, Enterobacter, Hafnia, Micrococcus, Mycobacterium, Nocardia, Pseudomonas, Rathayibacter, Rhodococcus, Salmonella, Serratia, Staphylococcus, Variovorax y Xantomonas (Ellis et al, 2003).

La ingeniería genética permite la introducción de rasgos deseables en las células microbianas para lograr técnicas de remediación más eficientes (Marrero et al, 2010); el mejoramiento genético puede 
Tabla 3. Algunas plantas implicadas en procesos de fitorremediación de metales pesados.

\begin{tabular}{|c|c|c|}
\hline Planta & Metal & Referencia \\
\hline Salvinia natans Kunth. & $\mathrm{Cd}$ & Buta et al, 2014 \\
\hline Eichhornia crassipes Mart. & $\mathrm{Cd}, \mathrm{Cr}$ & $\begin{array}{c}\text { Zhu et al, 1999; Dos Santos y Lenzi, 2000; } \\
\text { Prasand y Freitas, 2003; Jafari, 2010; Kumar, } \\
\text { 2010; Mane et al, 2010; Carrión et al, 2012; } \\
\text { Chattopadhyay et al, 2012; Saleh, 2012; Sood } \\
\text { et al, 2012; Borker et al, 2013; Buta et al, 2014, } \\
\text { Swain et al, 2014. }\end{array}$ \\
\hline Lemna minor $L$. & $\mathrm{Cd}, \mathrm{Cr}, \mathrm{Hg}$ & $\begin{array}{l}\text { Prasand y Freitas, 2003; Kumar, 2010, } \\
\text { Bharti y Banerjee, 2013, Ücüncü et al, 2013; } \\
\text { Buta et al, } 2014 .\end{array}$ \\
\hline Elodea canadensis Michx. & $\mathrm{Cd}$ & Buta et al, 2014 \\
\hline Pistia stratiotes $L$. & $\mathrm{Cd}$ & $\begin{array}{l}\text { Prasand y Freitas, 2003; Buta et al, 2014; Kumar } \\
\text { et al, 2012; Akinbile et al, } 2012 .\end{array}$ \\
\hline $\begin{array}{c}\text { Limnocharis flava, Thalia geniculata, } \\
\text { Typha latifolia }\end{array}$ & $\mathrm{Hg}$ & Anning et al, 2013. \\
\hline Azolla pinnata & $\mathrm{Cr}, \mathrm{Hg}, \mathrm{Cd}$ & Kumar, 2010; Bharti y Banerjee, 2013. \\
\hline Spirulina platensis & $\mathrm{Cd}$ & Solisio et al, 2007; Rangsayatorn et al, 2002. \\
\hline $\begin{array}{l}\text { Brassica sp, Alyssum sp, } \\
\text { Arabidopsis sp, Petrisis sp }\end{array}$ & $\mathrm{Cr}$ & Kamnev y van der Lelie, 2000. \\
\hline Thlapsi sp & $\mathrm{Cd}$ & Prasand y Freitas, 2003. \\
\hline Ipomoe aquiatica & $\mathrm{Cr}$ & Weerasinghe et al, 2008. \\
\hline Helianthus annuus & $\mathrm{Cd}, \mathrm{Cr}$ & Buta et al, 2014 \\
\hline Spirulina platensis & $\mathrm{Cd}$ & $\begin{array}{l}\text { Zhu et al, 1999; Dos Santos y Lenzi, 2000; } \\
\text { Prasand y Freitas, 2003; Jafari, 2010; Kumar, } \\
\text { 2010; Mane et al, 2010; Carrión et al, 2012; } \\
\text { Chattopadhyay et al, 2012; Saleh, 2012; } \\
\text { Sood et al, 2012; Borker et al, 2013; } \\
\text { Buta et al, 2014, Swain et al, 2014. }\end{array}$ \\
\hline
\end{tabular}


contribuir a optimizar las tecnologías utilizadas en procesos de descontaminación, el uso de la genómica, proteómica y la metabolómica puede proveer información acerca de las rutas metabólicas, con el fin de identificar genes, proteínas o metabolitos involucrados en la tolerancia u oxidación de los metales (Kavaruma y Esposito, 2010).

Se conoce que los determinantes genéticos que codifican proteínas involucradas en los mecanismos de resistencia a metales, se encuentran generalmente localizados en el cromosoma bacteriano, en elementos móviles como plásmidos o transposones o en ambos. Los plásmidos que confieren resistencia a metales poseen gran especificidad y son sistemas inducibles en la mayoría de los casos; hasta el momento se han descrito genes de resistencia a plata $(\mathrm{Ag})$, arsénico $(\mathrm{Ar})$, cadmio $(\mathrm{Cd})$, cromo $(\mathrm{Cr})$, cobre $(\mathrm{Cu})$, mercurio $(\mathrm{Hg})$, niquel $(\mathrm{Ni})$, plomo $(\mathrm{Pb})$, antimonio (Sb) y cinc (Zn) localizados en grandes plásmidos (165-200 kb) (Shukla, 2006; Marrero et al, 2010).

Así mismo, se ha encontrado que algunos sistemas de resistencia a metales están codificados por genes cromosomales en algunos microorganismos como es el caso de Bacillus sp. que mostró resistencia contra mercurio. Kavaruma y Esposito (2010), realizaron estudios con Bacillus subtilis con el fin de estudiar los genes que se expresan por la exposición a metales, identificando que diferentes tipos de genes afectados fueron regulados por proteínas metaloregulatorias conocidas como Fur, MntR, Per $R$, ArsR y CueR.

En estudios de biorremediación de Hg se están usando técnicas moleculares para construir bacterias genéticamente modificadas que pueden coexpresar las proteínas transportadoras de mercurio MerT - MerP con metalotioneinas o péptidos de unión a metales que acumulan Hg (Kavaruma y Esposito, 2010). Aunque los microorganismos solo en raras ocasiones producen metalotioneínas, Garbisu et al, 2003 encontraron que un gen de ratón que codifica para la producción de metalotioneinas podría ser expresado en Ralstonia eutropha. El ejemplo más conocido de determinantes de resistencia a metales localizados en transposones es el locus mer presente en los megaplásmidos de Cupriavidus metallidurans que confiere resistencia a Hg (Marrero et al, 2010).

En estudios de biorremediación de Cd se modificó un aislamiento de $R$. eutropha resistente a metales con el objetivo de producir metalotioneinas y de esa forma acumular más $\mathrm{Cd}^{2+}$ que su contraparte, la cepa nativa, en este estudio la cepa modificada ofreció cierto grado de resistencia a $\mathrm{Cd}^{2+}$ para las plantas de tabaco después de ser inoculadas en un suelo contaminado (Rajendran et al, 2003). En otra aproximación se expresó un gen de Arabidopsis thaliana que codifica para la Fitoquelatina sintasa y se logró incrementar la acumulación de $\mathrm{Cd}^{2+}$ en Mesorhizobium huakuii subsp. Rengei B3 y Escherichia coli (Wu et al, 2010).

Kavamura y Esposito en el 2010, usando un análisis transcripcional del genoma total de Caulobacter crescentus identificaron las rutas bioquímicas que responden a la toxicidad con metales, esta bacteria es conocida por su habilidad de vivir en ambientes con presencia de metales y por tolerar $\mathrm{Cd}$ y $\mathrm{Cr}$, debido posiblemente a la protección contra el estrés oxidativo y múltiples bombas de flujo. Plásmidos que codifican sistemas de flujo de metales dependientes de energía que involucran ATPasas y bombas de protones quimiosmóticas están asociadas a la resistencia de $\mathrm{Ar}, \mathrm{Cr}$ y $\mathrm{Cd}$ en Staphylococcus aureus, Bacillus subtilis, Listeria sp, Escherichia coli, Alcaligenes. eutrophus, Pseudomonas putida y algunas cianobacterias algas y hongos (Roane et al, 2000; Rajendran et al, 2003).

El plásmido que contiene el gen cad A codifica para una ATPasa específica para Cd en varios géneros bacterianos como Staphylococcus sp., Pseudomonas sp. y Bacillus sp. Por su parte, Rajendran et al, 2003 reportaron que los operones czc y ncc son responsables de la resistencia a $\mathrm{Cd}$ en Alcaligenes 
eutropha CH34 ahora llamado Ralstonia eutropha y en Achromobacter xylosoxidans respectivamente.

Finalmente microorganismos genéticamente modificados como Escherichia coli que expresan proteínas de unión y sistemas de transporte específicos para metales, han mostrado ser efectivos en la acumulación selectiva de metales y de agentes quelantes en solución (Chen y Wilson, 1997).

\section{Plantas genéticamente modificadas}

En años recientes la utilización de técnicas de ingeniería genética ha venido en aumento debido a que algunas de las plantas hiperacumuladoras naturales no satisfacen las necesidades de remoción debido a su bajo crecimiento, su baja producción de biomasa y su demanda de nutrientes debido a las condiciones de crecimiento ( $\mathrm{Wu}$ et al, 2010). Algunos científicos han empleado técnicas de ingeniería genética mostrando buenos resultados en la conversión y movilización de metales por parte de plantas. El conocimiento de la fisiología, bioquímica y biología molecular en respuesta a contaminantes específicos es crítico para la optimización y avance de la fitoremediación (Maiti et al, 2004).

A nivel molecular los mecanismos de acumulación y transporte de iones por las plantas están parcialmente clarificados, muchos transportadores codificados por genes específicos han sido investigados y es común que un tipo de ion metálico pueda ser transportado por diferentes proteínas transportadoras (Zhao et al, 1999; Wu et al, 2010). Las especies vegetales transgénicas expresan la proteína organomercurial liasa (MerB) y tienen una mayor tolerancia a complejos de $\mathrm{Hg}$ orgánico que las especies silvestres y pueden convertir metilmercurio a $\mathrm{Hg}$ (II) que es 100 veces menos tóxico. Otras plantas transgénicas expresan la proteína MerA (mercurio reductasa) que reduce $\mathrm{Hg}$ (II) a Hg (0) (Wu et al, 2010).

La transferencia de rasgos para la hiperacumulación de plantas es posible mediante la hibridización somática en la cual se obtienen plantas híbridas a partir de la fusión de protoplastos derivados de células somáticas (Samantaray et al, 2001). Gracias a los avances en ingeniería genética muchos genes que brindan resistencia a metales pesados han sido introducidos dentro de las células vegetales. Debido a la sobreexpresión de quelantes naturales como MT's, FQ's y ácidos orgánicos y gracias a la trasferencia de genes, no solo la entrada de iones a la célula se facilita, sino también la traslocación al xilema y a otras partes de la planta. La introducción de genes que codifican para ciertas proteínas trasportadoras, permiten en las plantas la trasformación de la valencia del metal, lo que genera formas menos tóxicas o más volátiles (Wu et al, 2010).

El uso de genes de bacterias expresados en plantas induce la capacidad de remoción de compuestos de Hg (Maiti et al, 2004), en la actualidad muchos genes de resistencia a metales pesados han sido introducidos en células vegetales (Wu et al, 2010). Lee et al, 2003 expresaron el gen ZntA de E.coli que codifica para una bomba de $\mathrm{Pb}(\mathrm{II}), \mathrm{Cd}(\mathrm{II})$ y $\mathrm{Zn}(\mathrm{II})$ en células de Arabidopsis sp., observando una alta resistencia a los metales por parte de la planta como también una baja acumulación de estos en sus tejidos. Así mismo al inocular Pseudomonas putida en raíces de Helianthus annus modificada genéticamente, se incrementó la acumulación de $\mathrm{Cd}$ por parte de la planta y se redujo notablemente su fitotoxicidad (Wu et al, 2006).

\section{CONCLUSIONES}

Los microorganismos cuentan con amplias capacidades metabólicas que les permiten utilizar diferentes tipos de sustratos con el objetivo de obtener energía y en muchos casos transformarlos, los metales pesados son sustratos que pueden ser inmovilizados o transformados por estos organismos utilizando diversas estrategias lo cual puede afectar su biodisponibilidad. Esta situación ha permitido que 
se puedan implementar técnicas de biorremediación que involucren el uso de hongos y bacterias con el fin de reducir la carga contaminante de diversos ambientes. La utilización de técnicas de ingeniería genética ha permitido manipular cepas microbianas que exhiben naturalmente buenas capacidades biorremediadoras para generar microorganismos con capacidades potenciadas que muestran resultados promisorios en estudios a nivel in vitro y a nivel de campo, sin embargo, los mejores resultados se han obtenido al utilizar en conjunto las capacidades de plantas y microorganismos en un mecanismo conocido como simbiótico.

Las plantas hiperacumuladoras (metalófitas) tienen la capacidad para remover, reducir, transformar, mineralizar, degradar, volatilizar o estabilizar metales pesados gracias a su alta capacidad de acumulación en las raíces y translocación diferentes órganos vegetativos alcanzando niveles de remoción de hasta del 100\%. Dentro de las adaptaciones fisiológicas y bioquímicas se incluye el desarrollo de estructuras complejas llamadas metal-proteínas o metalotioneinas, que permiten el control en la acumulación de $\mathrm{Cd}, \mathrm{Cr}$ y Hg, que además le brindan protección a la célula ante efectos tóxicos. Por otra parte, gracias a los avances en ingeniería genética muchos genes que generan resistencia a metales pesados han sido introducidos dentro de las células vegetales, como es el caso de las especies vegetales transgénicas que expresan las proteínas organomercurial liasa (MerB) y MerA (mercurio reductasa), presentan una mayor tolerancia a complejos de $\mathrm{Hg}$ orgánico y reduciendo $\mathrm{Hg}$ (II) a $\mathrm{Hg}$ (0).

La microremediación y la fitorremediación son consideradas tecnologías promisorias en el tratamiento de la contaminación de metales pesados, su utilización en campo y laboratorio evidencian el potencial biotecnológico en la recuperación de ambientes afectados. El conocimiento de los procesos metabólicos y genéticos de microorganismos y plantas, permite el desarrollo y aplicación de técnicas efectivas en procesos de biorremediación.

\section{REFERENCIAS}

1 Adelaja O, Keenan H. 2012. Tolerance of TBTresistant bacteria isolates to methylmercury. Res J Environ Sci, 6(1):1-13.

2 Ahuja V, Vohra P, Kashyap D, Tewari R. 2001. Adsorption of heavy metals $\left(\mathrm{Pb}^{+2}\right.$ and $\left.\mathrm{Cd}^{+2}\right)$. by free and immobilized biomass of Acinetobacter anitratus. 41:275- 279.

3 Akpor O, Muchie M. 2010. Remediation of heavy metals in drinking water and wastewater treatment systems: Processes and applications. International Journal of the Physical Sciences, 5(12):1807-1817.

4 Ali N, Hameed A, Ahmed S. 2009. Physicochemical characterization and bioremediation perspective of textile effluent, dyes and metals by indigenous bacteria. Journal of hazardous materials, 164:322-328.

5 Anning A, Korsah P, Addo P. 2013. Phytoremediation of wastewater with Limnocharis Flava, Thalia Geniculata and Typha Latifolia in constructed wetlands. Internal J. Phytorem, 15 (5):452-464.

6 Babich H, Stotzky G. 1977. Effect of cadmium on fungi and on interactions between fungi and bacteria in soil: influence of clay minerals and pH. Appl Environ Microbiol, 33:1059-1066.

7 Baghour M, Moreno D, Villora G, Hernández J, Catilla N, Romero L. 2001. Phytoextraction of $\mathrm{Cd}$ and $\mathrm{Pb}$ and physiological effects in potato plants (Solanum tuberosum var. Spunta): Importance of root temperature. Journal Agric anf Food Chem. Chem, 49:5356-5363. 
8 Bayramoglu G, Arica M. 2008. Removal of heavy mercury (II), cadmium (II) and zinc (II) metal ions by live and heat inactivated Lentinus edodes pellets. Chem Eng Journal, 143(13): 133-140.

9 Bharti S, Banerjee T. 2013. Bioassay analysis of efficacy of phytoremediation in decontamination of coal mine effluent. Ecotoxicology and Environmental Safety, 92:312-319.

10 Bolan N, Kunhikrishnan A, Thangarajan R, Kumpiene J, Park J, Makino T, Kirkham M and Scheckel K. 2014. Remediation of heavy metal (loid)s contaminated soils-to movilize or to immobilize. Journal of Hazardous Material, 266: 141-166.

11 Borker A, Mane A, Saratale G, Pathade G. 2013. Phytoremediation potential of Eichhornia crassipes for the treatment of cadmium in relation with biochemical and water parameters. Emir. J. Food Agric, 25 (6):443-456.

12 Borremans B, Hobman J, Provoost A, Brown N, van Derlelie D. 2002. Cloning and functional analysis of the pbr lead resistance determinant of Ralstonia metallidurans CH34. J Bacteriol, 183:5651-5658.

13 Bricker T, Pichtel J, Brown H, Simmons M. 2001. Phytoextraction of $\mathrm{Pb}$ and $\mathrm{Cd}$ from a superficial soil: effects of amendments and cropping. Journal Environmental Sience and healt Enginerring, 36:1597-1610.

14 Buta E, Török A, Csog A, Zongo B, Cantor B, Buta M, Majdik M. 2014. Comparative studies of the phytoextraction capacity of five aquatic plants in heavy metal contaminated water. Not Bot Horti Agrobo, 42(1):173-179.

15 Cabral L, Giovanella P, Gianello C, Bento F, Andreazza R, Camargo F. 2012. Isolation and characterization of bacteria from mercurycontaminated sites in Rio Grande do Sul, brazil, and assessment of methylmercury removal capability of a Pseudomonas putida V1 strain. Biodegradation, 24:319-31.

16 Campos J, Martínez M, Cervantes C.1995. Hexavalent chromium reduction by a chromate-resistant Bacillus strain. Anton Leeuw, 68:203-208

17 Cañizares R. 2000. Biosorción de metals pesados mediante el uso de biomasa microbiana. Rev Lat Microb, 42:131-143.

18 Carrión C, Ponce-de León C, Cram C, Sommer I, Hernández M, Vanegas C. 2012. Potential use of water hyacinth (Eichhornia crassipes) in Xochimilco for metal phytoremediation. Agroc, 46:609-620.

19 Chaney R, Angle J, Broadhurst C, Peters C, Tapero R, Sparks D. 2007. Improved understanding of hyperacumulation yields commercial phytoextraction and phytomining technologies. J Environmental Qual, 36:1429-1443.

20 Chatterjee S, Bhattacharjee I, Chandra G. 2010. Biosorption of heavy metals from industrial waste water by Geobacillus thermodenitrificans. Journal of Hazardous Materials, 175:117-125. 
21 Chaudhry O, Blom- Zandstra M, Gupta S, Joner E. 2005.Utilising the synergy between plants and rhizosphere microorganisms to enhance breakdown of organic pollutants in the environment. Environ Sci. Pollut Res, 12:34-48.

22 Chen S, Wilson D. 1997. Genetics engineering of bacteria and their potential for $\mathrm{Hg}^{+2}$ bioremediation. Biodegradation, 8:97-103.

23 Choppala G, Bolan N, Kunhikrishnan A, Skinner W, Seshadri B. 2013. Concomitant reduction and immobilization of chromium in relation to its bioavailability in soils. Environ. Sci. Pollut. Res, DOI 10.1007/s1 1356-013 1653-6.

24 Cobbeett C. 2000. Phytochelatin biosynthesis and function in heavy-metal detoxification. Plant physiol, 123:825-832.

25 Cunningham S, Berti W, Huang J. 1995. Phytoremediation of contaminated soils. Trends Biotechnol, 13:393-397.

26 Dash H, Mangwani N, Chakraborty J, Kumari S, Das S. 2013. Marine bacteria: potential candidates for enhanced bioremediation. Appl Microbiol Biotechnol, 97:561-571.

27 Dhal B, Thatoi H, Das N, Pandey B. 2013. Chemical and microbial remediation of hexavalent chromium form contaminated soil and mining/ metallurgical solid waste: A review. Journal of hazardous materials, 250-251:272-291.

28 Dos Santos M, Lenzi E. 2000. The use of aquatic macrophytes (Eichhornia crassipes) as a biological filter in the treatment of lead contaminated effluents. Environ Technol, 21:15-622.

29 Ellis R, Morgan P, Weightman A, Fry J. 2003. Cultivation-dependent and independent approaches for determining bacterial diversity in heavy metal-contaminated soil. Appl Environ Microbiol, 69:3223-3230.

30 Favas P, Pratas J, Prasad M. 2012. Accumulation of arsenic by aquatic plants in large-scale field conditions: Opportunities for phytoremediation and bioindication. Science of the Total Environment, 433:390-397.

31 Garbisu C, Alkorta I. 2003. Basic concept son heavy metal soil bioremediation. European Journal of mineral processing and environmental protection, 3: 58-66.

32 Garbisu C, Alkorta, I.1997. Bioremediation: principles and future. Journal of Clean Technology, Environmental Toxicology and Occupational Medicine, 6:1-16.

33 Gilis A, Khan M, Cornelis P, Meyer J, Mergea M, van der Lelie D. 1996. Siderophore-mediated iron uptake in Alcaligenes eutrophus $\mathrm{CH} 34$ and identification of aleB encoding ferric-alcaligin E receptor. J. Bact, 178:5499-5507.

34 Ginn B, FEIN J. 2008. The effect of species diversity on metal adsorption onto bacteria. Geochim Cosmochim Acta, 72:939-3948.

35 Gupta R, Ahuja P, Khan S, Saxena R, Mohapatra H. 2000.Microbial biosorbents: Meeting challenges of heavy metal pollution in aqueous solution. Curr Sci, 78 (8):967-973. 
metal contaminated soils. J. Zhejiang Univ Sci, 8:192-207.

44 Juwarkar A, Nair A, Dubey K, Singh S, Devotta S. 2007. Biosurfactant technology for remediation of cadmium and lead contaminated soils. Chemosphere, 68:1996-2002.

45 Kamnev A, Van der Lelie D. 2000. Chemical and Biological parameters as tools to evaluate and improve heavy metal phytoremediation. Biosci. Rep, 29:239 - 258.

46 Kavaruma V, Esposito E. 2010. Biotechnological strategies applied to the descontamination of soils polluted with heavy metals. Biotechnology advances, 28:61-69.

47 Khade S, Adholeya A. 2007. Feasible bioremediation through arbusculares. mycorrhizal fungi imparting heavy metal tolerance: a retrospective. Bioremediation Journal, 11:33-43.

48 Khan A. 2006. Mycorrhizoremediation- an enhanced form of phytoremediation. J Zhejiang Univ Sci, 7:503-14.

49 Kim S, Park C, Koo Y, Yun H. 2003. Biosorption of cadmium and cooper ions by Trichoderma reesei RUT C30. J Ind Eng Chem, 9:403-406.

50 Kneer R, Zenk M. 1992. Phytochelatins protect plant enzymes from heavy-metals poisoning. Phytochem, 31:2663.

51 Kukier U, Chaney R. 2000. Influence of the zinc hyperacumulator. Canad J. soil Sci, 80:581-593.

52 Kumar S, Neelima M, Sing S. 2012. Phytorremediation of chromium and cobalt using Pistia 
sratiotes: A sustainable approach. Proceeding of the international Academy of Ecology and Environmental Sciences, 2(2):136-138.

53 Lasat M. 2000. Phytoextraction of metals from contaminated soil: a review of plan/soil/metal interaction and assessment of pertinent agronomic issues. J. Hazard Subst Res, 2: 5-25.

54 Lee S, Chung J, Won H, Lee D, Lee. 2012. Removal of the methylmercury and tributyltin (TBT) using marine microorganisms. Bull Environ Contam Toxicol, 88:239-244.

55 Li X, Feng M, Syuntaro H. 2000. Mucilage strongly binds aluminum but does not prevent roots from aluminum injury in Zea mays. Physiology Plantarium, 108:152-160.

56 Li Y, Chaney R, Brewer E, Roseberg R, Angle J, Baker A, Reeves R, Nelkin J. 2003. Development of a technology for commercial phytoextraction of nickel: economic and technical considerations. Plant soil, 249:107-115.

57 Liu W, Marsh T, Cheng H, Forney L. 1997. Characterization of microbial diversity by determining terminal restriction fragment length polymorphisms of gene encoding 16S rRNA. Appl. Environ. Microbiol, 63:4516-4522.

58 Lone M, Zhen-li H, Stoffella P, Xiao-e Y. 2014. Phytoremediation of heavy metal polluted soils and water: Progresses and perspectives. J Zhejiang Univ Sci B, 9(3):210- 220.

59 Long D, Tanga X, Caib K, Chena G, Chena I, Duana D, Zhuc J, Chena Y. 2013 Cr(VI) reduction by a potent novel alkaliphilic halotolerant strain Pseudochrobactrum saccharolyticum
LY10. Journal of Hazardous Materials, 256- 257:24-32.

60 Loseto L, Siciliano S, Lean D. 2004. Methylmercurio production in high Arctic wetlands. Environ Toxicol Chem, 23:17-23.

61 Loutseti S, Danielidis D, Economou-amili A, Katsaros C, Santas R, Santas P. 2009. The application of a micro-algal/bacterial biofilter for the detoxification of cooper and cadmium metal wastes. Biore Technol, 100:2099-2105.

62 Lovley D, Lloyd J. 2000. Microbes with a metal for bioremediation. Nature Biotechnology, 18 : 600-601.

63 Lucho C, Alvaréz M, Beltrán R, Prieto F, Poggi H. 2005. A multivariate analysis of the accumulation and fractionation of major and trace elements in agricultural soils in Hidalgo State, Mexico irrigated with raw wastewater. Environmental international: a journal of environmental science, risk and health, 31(3): 313-323.

64 Luo C, Shen Z, Lou L, Li X. 2006. EDDS and EDTA-enhanced phytoextraction of metals from artificially contaminated soil and residual effects of chelant compounds. Environ. Pollut. 144:862-871.

65 Maiti R, Hernández J, González J. lópez D. 2004. Plant based biorremediation and mechanism of heavy metal tolerance of plants. Proc. Indian natan Sci Acad, 70 (1):1-12.

66 Mane A, Saratale V, Karadge B, Samant S. 2011. Studies on the effects ofsalinity on growth, polyphenol content and photosynthetic 
response in Vetiveria zizanioides (L.) Nash. Emir. J. Food Agric, 23:59-70.

67 Marrero J, Díaz A, Coto O. 2010. Mecanismos moleculares de resistencia a metales pesados en las bacterias y sus aplicaciones en la Biorremediación. Revista CENIC Ciencias Biológicas, 41 (1): 67-78.

68 McGrath S, Zhao F, Lombi E. 2001. Plant and rhizosphere process involved in phytoremediation of metal-contaminated soils. Plant Soil, 232:207-214.

69 Miller M, Bassler B. 2006. Quorum sensing in bacteria. Annu Rev Microbiol, 55:165-199.

70 Muyzer G, de Waal E, Uitterlinden A. 1993. Profiling of complex microbial populations by denaturing gradient gel electrophoresis analysis of polymerase chain reaction-amplified genes coding for $16 \mathrm{~S}$ rRNA. Appl. Environ. Microbiol, 59:695-700.

71 Navari-izzo F, Quartacci M. 2011. Phytoremediation of metals. Minerva Biotechnol, 13:73-83.

72 Nessner V, Esposito E. 2010. Biotechnological strategies applied to the decontamination of soil polluted with heavy metals. Biotechnology advances, 28:61-89.

73 Nies D. 1999. Microbial heavy metal resistance. Applied Microbiology Biotechnology, 51: 730-750.

74 Padmavathiamma P, Li L. 2007. Phytoremediation Technology: Hyperaccumulation Metals in Plants. Water, Air, \& Soil Pollution, 184:105-126.

75 Paisio C, González P, Talano M, Agostini E. 2012. Remediación biológica de Mercurio:
Recientes avancesRev Latinoam Biotecnol Amb Algal, 3(2):119-146.

76 Paz-Ferreiro J, Lu H, Fu S, Méndez A, Gascó G. 2014. Use of phytorremediation and biochar to remediate heavy metal polluted soils: a review. Solid Earth, 5:65-75.

77 Pepi M, Gaggi C, Bernardirni E, Focardi G, Lobianco A, Ruta M, Nicolardi V, Volterrani M, Gasperini S, Trinchera G, Renzi P, Gabellini M, Focardi S. 2011. Mercury resistant bacterial strains Pseudomonas sp and Psychrobacter sp isolated form sediments of Orbetello Lagoon (Italy) and their possible use in bioremediation processes. Int Biodet Biodeg 65(1):85-91.

78 Prasad M, Freitas H. 2003. Metal hyperaccumulation in plants-Biodiversity prospecting for phytoremediation technology. Electron. J. Biotechnol 93(1):285-321.

79 Rajendran P, Muthukrishnan J, Gunasekaran P. 2003. Microbes in heavy metal remediation. Indian Journal of Experimental Biology, 41: 935-944.

80 Ramteke P. 2000. Biosorption of Nickel (II) by Pseudomonas stutzeri. J Environ Biol, 21:219-221.

81 Rascio N, Navari-izzo F. 2011. Heavy metal hyperaccumulating plants: How and why do they do it? And what makes them so interesting? Plant Sci. 180:169-181.

82 Raspanti E, Cacciola S, Gotor C, Romero L, Garcia I. 2009. Implications of cyste-inemetabolism in the heavy metal response in Trichoderma harzianum and in three Fusarium species. Chem, 76:48-54. 
83 Roane T, Pepper I. 2009. Microorganisms and metal pollution. Environmental Microbiology.1 .ed. London (England): Academic press. p 632.

84 Saleh H. 2012. Water hyacinth for phytoremediation of radioactive waste simulate contaminated with cesium and cobalt radionuclides. Nucl Eng Des, 242:425-432.

85 Salt D, Blaylock m. Kumar N, Dushenkov V, Ensley B, Chet I, Raskin I. 1995. Phytoremediation: a novel strategy for the removal of toxic metals from the environment using plants. Biotechnol, 13(5):468-74

86 Samantaray S, Rout G, Das P. 2001. Induction, selection and characterization of $\mathrm{Cr}$ and $\mathrm{Ni}$ tolerant cell lines of Echinochloa colona (L). Link in vitro. J Plants Physiol 158:1281-1290.

87 Sambandan K, Kannan K, Raman N. 1992. Distribution of vesicular-arbuscular mycorrhizal fungi in heavy metal polluted soils of Tamil Nadu, India. J. Environ. Biol. 13:159-167.

88 Samuelson P, Wernerus H, Svedberg M, Stahl S. 2000. Sthaphylococcal surface display of metal binding polyhistydiyl peptides. Appl Environ Microbiol, 66:1092-1096.

89 Shukla O, Rai U, Dubey S, Mishra K. 2006. Bacterial resistance: A tool for remediation of toxic metal pollutants. Environ News, 12:2-4.

90 Sinha A, Pant H, Khare S. 2012. Mercury bioremediation by mercury accumulating Enterobacter sp cells and its alginate immobilized application. Biodegradation, 23(1):25-34.
91 Solisio C, Lodi A, Soletto D, Converti A. 2007. Cadmium Biosorption on Spirulina platensis biomass. Bioresource Technol, 99:5933-5937.

92 Soto C, Gutiérrez S, Rey A, González, E. 2010. Biotransformación de metales pesados presentes en lodos ribereños de los ríos Bogotá y Tunjuelo, NOVA 8:195-205.

93 Swain G, Adhikari P, Mohanty. 2014. Phytoremediation of Copper and Cadmium from Water Using Water Hyacinth, Eichhornia crassipes. Internal J. Agric Sci and Technol. 2(1):1-7.

94 Üçüncü E, Tunca E, Fikirdeşici S, Özkan D, Altindaǧ. 2013. Phytoremediation of $\mathrm{Cu}, \mathrm{Cr}$ and $\mathrm{Pb}$ Mixtures by Lemna minor. Bull Environ Contam Toxicol, 91:600-604.

95 Ullrich A, Tanton T, Abdrashitova S. 2001. Mercury in aquatic environment: a review of factors affecting methylation. Crit Rev Environ Sci Technol, 31: 241-293.

96 Valls M, Atrian S, De Lorenzo V, Fernandéz L. 2000. Engineering a mouse metallothionein on the cell surface of Ralstonia eutropha $\mathrm{CH}_{34}$ for inmovilization of heavy metals in soil. Nat Biotechnol 18: 661-665.

97 Vasudevan P, Padmavathy $\mathrm{V}$, Tewari V, Dhingra S. 2001. Biosorption of heavy metals. Journal Science and Industrial Research, 60: 112-120.

98 Wang P, Mori T, Komori K, Sasatsu K, Toda K, Phtake H. 1989. Isolation and characterization of and Enterobacter cloacae strains 
that reduces hexavalent chromium under anaerobic conditions. App. Environ. Microbiol 55:1665-1669.

99 Weerasinghe A, Aruyawnasa S, Weerasooriya R. 2008. Phytoremediation potential of Ipomea aquatica for $\mathrm{Cr}$ (IV) mitigation. Chemosphere, 70:521-524.

100 Wiatrowski H, Ward P, Barkay, T. 2006. Novel reduction of mercury (II) by mercury-sensitive dissimilatory metal reducing bacteria. Environ Sci Technol, 40:6690-6696.

101 Wu G, Kang H, Zhang X, Shao H, Chu L, Chengjiang R. 2010. A critical review on the bio-removal of hazardous heavy metal from contaminated soil: Issues, progress, eco-environmental concerns and opportunities. Journal. Hazardous Materials, 174:1-8.

102 Zheng Y, Fang X, Ye Z, Li Y, Cai W. 2008. Biosorption of $\mathrm{Cu}$ (II) on extracelular polymers from Bacillus sp. F19. J. Environmental Science, 119:1288-1293.

103 Zhu Y, Zayed A, Qian J, de Souza M, Terry N. 1999. Phytoremediation of trace elements by wetland plants: II. Water Hyacinth. J. Environ. Qual, 28:339-344.

104 Zimmer D, Baum C, Leinweber P, Hrynkiewicz K, Missner R. 2009. Associated bacteria increase the phytoextraction of cadmium and zinc from a metal-contaminated soil by mycorrhizal willows. Int J Phytoremediat, 11:200-213. 